\title{
Evidence of short spatial variability of the equatorial electrojet at close longitudinal separation
}

\author{
N Phani Chandrasekhar ${ }^{1,2^{*}}$, Kusumita Arora ${ }^{1}$ and Nandini Nagarajan ${ }^{1}$
}

\begin{abstract}
The characteristics of longitudinal variability of equatorial electrojet (EEJ) and counter electrojet (CEJ), presented in this study, are based on concurrent observations from a hitherto unsampled region of the world to examine the (1) degree of correlation between hourly means and monthly averaged hourly means of ground observations with equatorial electrojet climatological model (EEJM-2.0), (2) day-to-day longitudinal variability of EEJ strength between the pairs of sites, and (3) longitudinal variability in occurrences of counter electrojet. The analyses are based on the data obtained from an observatory and three new remote sites in the northern Indian Ocean at a longitudinal separation of approximately $15^{\circ}$ : Hyderabad (HYB) and Vencode (VEN) at $77^{\circ} \mathrm{E}$ and Port Blair (PBR) and Campbell Bay (CBY) at $93^{\circ} \mathrm{E}$, for a period of 4 months during Lloyd's D-season (November 2011 to February 2012) and comparison with the EEJM-2.0 based on CHAMP satellite data.

At both longitudes, the overall correlation of monthly mean hourly values (i.e., from 05:00 to 19:00 LT) between the observed EEJ strength and modeled current density from EEJM-2.0 is good $(r>0.8)$. However, a significant lack of correlation is witnessed on day-to-day peak values (i.e., 12:00 LT) between the observed variations and the model at both sites. Further, a comparison of noontime peaks between the two sites shows a considerable day-to-day variability. A large number of CEJs (43 events) are recorded during the study: at CBY (15 events) and VEN (28 events). Analyses of the CEJ events highlight the variability of CEJ phenomena in terms of amplitude, dates, and time of occurrence over $15^{\circ}$ longitude separation. The local nature of perturbations causing CEJ is evident; the possible factors are being non-migrating eastward and westward propagating diurnal tides and local meteorological phenomena associated with upper mesospheric temperature, wind, and density variations.
\end{abstract}

Keywords: Equatorial electrojet; Counter electrojet; lonosphere; Day-to-day variability

\section{Background}

The equatorial electrojet

The two or three fold enhancement in the daily variation of the horizontal component of the earth's magnetic field $(\mathrm{H})$, within a narrow belt of latitudes $\left( \pm 3^{\circ}\right)$ over the dip equator (Egedal 1947), is caused by an eastward current in the E-region of the ionosphere, called the equatorial electrojet (EEJ) (Chapman 1951). The strength of the electrojet current in a particular longitude zone is determined by deducting the diurnal range of $\mathrm{H}$ or $\mathrm{X}$ component at a

\footnotetext{
* Correspondence: phaninelapatla@gmail.com

'Magnetic Observatory, CSIR-National Geophysical Research Institute, Hyderabad 500007, India

2Department of Geophysics, Andhra University, Vishakhapatnam 530003,
} India

\section{Springer}

(c) 2014 Chandrasekhar et al.; licensee Springer. This is an Open Access article distributed under the terms of the Creative Commons Attribution License (http://creativecommons.org/licenses/by/4.0), which permits unrestricted use, distribution, and reproduction in any medium, provided the original work is properly credited.

\section{Longitudinal dependence of the EEJ}

Day-to-day variability of the EEJ, at a site or between longitudinally separated sites, is amply documented between different longitudinal sectors (Rastogi 1962b) as well as from satellite observations (Langel et al. 1993). More refined models of longitudinal variability of EEJ were developed after the launch of the three magnetic field mapping satellites, Oersted (1999 to present), CHAMP (2000

low-latitude (non-EEJ) station from the diurnal range of $\mathrm{H}$ $\mathrm{X}$ component at the equatorial (EEJ) station, in the longitudinal zone. The width of the EEJ varies condip equator at an altitude of $106 \mathrm{~km}$ (Chapman 1951; Onwumechili 1985). 
to 2010), and SAC-C (2001 to 2004), provided an improved database. Statistical correlations for day-to-day variation of EEJ strength and solar wind parameters from ground and satellite data indicate good correlation between the two (Rastogi and Chandra, 1974). Jadhav et al. (2002) derived the day-to-day EEJ strength using the satellite and simultaneous ground magnetic observatory data for the Indian and American sectors, corroborating the results of analysis made by Rastogi (1962b). The correlation of the EEJ with itself in longitude has been studied by Manoj et al. (2006) by correlating data from ground-based observatories and the CHAMP satellite at different longitudes and found a correlation drop of 0.7 , when measurements are compared from sites further apart than $15^{\circ}$ in longitude. Alken and Maus (2007) found short spatial and temporal correlation lengths of about $15^{\circ}$ based on the correlation fit of CHAMP and Oersted data sets as a function of longitude. Rastogi et al. (2007) showed a strong correlation of equatorial electrojet between two longitudes separated by $2,000 \mathrm{~km}$ (approximately $18^{\circ}$ longitude). The recent work by Adimula et al. (2011) again discussed the longitudinal variability in EEJ showing strongest electrojet strength in the South American sector (approximately $59^{\circ} \mathrm{W}$ ) with an average peak more than $100 \mathrm{nT}$ and weakest in Malaysian sector (approximately $101^{\circ} \mathrm{E}$ ) with $70 \mathrm{nT}$.

\section{The counter electrojet}

The instances of daytime values of EEJ strength, falling below nighttime values for a few hours, are commonly observed and are defined as counter electrojet (CEJ) (Gouin and Mayaud 1967). CEJ is known to occur during magnetically disturbed as well as during magnetically quiet conditions (Kikuchi et al. 2003; Rastogi 1974; McCreadie 2004).

The occurrence of CEJs is mostly observed during few hours after dawn and before dusk and is rarely observed around local noon (Mayaud 1977; Marriot et al. 1979). CEJs have also been detected from satellite-based studies (Cain and Sweeney 1973; Onwumechili 1985; Cohen and Achache 1990; Langel et al. 1993). Doumouya et al. (1998) investigated the seasonal variability in morning and afternoon CEJ events based on a 20-month data set at a West African longitude zone and concluded that EEJ amplitudes are weak during morning and afternoon CEJs observed on the same day. The characteristics of CEJ and influence of solar cycle, seasonal and lunar phase, and longitudinal and wind-derived atmospheric tides have been illustrated using ground magnetometer and Oersted observations in Indian and American regions (Vichare and Rajaram 2011). Changes in the E-region irregularities and the reversal of ionospheric drifts have been associated with CEJ events (Fambitakoye et al. 1973; Rastogi 1974). The westward currents manifested during some instances of CEJs may be caused by reversal of the interplanetary magnetic field (IMF-Bz) component from south to north (Rastogi 1974; Sizova 2002; Francisca et al. 2013) and or atmospheric tidal effects (Bhargava et al. 1980; Somayajulu et al. 1993; Sridharan et al. 2002). Recent studies show that rise in atmospheric temperature connected with the phenomena of sudden stratospheric warming (SSW) exhibits positive correlation with occurrences of CEJs (Matsuno 1971; Liu and Roble 2002; Sridharan et al. 2009).

\section{Longitudinal variability of the CEJ}

A few studies have reported that there is a large day-today variability of the CEJ phenomena over $45^{\circ}$ longitude separation and sometimes occurs over a large longitudinal difference (Onwumechili and Akasofu 1972; Mayaud 1977). Alex and Mukherjee (2001) concluded that there are significant differences in occurrence of various CEJ events at two equatorial stations Trivandrum, India, and Addis Ababa, Ethiopia, separated by $40^{\circ}$ in longitude. Kane and Trivedi (1981) demonstrated the characteristics of CEJ events at two locations in the Brazilian region across the East and the West coasts of the South American sector, separated by less than $30^{\circ}$ longitude. Rangarajan and Rastogi (1993) investigated the afternoon CEJ events at equatorial stations Addis Ababa and Kodaikanal and concluded that the afternoon CEJ is localized in longitude, and on some occasions, the events may not occur on the same day even at locations separated by a narrow longitude of $2 \mathrm{~h}$.

\section{Objectives of the current study}

Observations from two sites, separated by only $15^{\circ}$ longitude from a hitherto unsampled region of the world during the period November 2011 to February 2012, are used to investigate the (1) degree of correlation between the ground EEJ observations and EEJM-2.0, (2) day-today variability in EEJ magnitude between the sites classified according to $\mathrm{Kp}$ (planetary index) values, and (3) variability in occurrences of counter electrojet events.

\section{Methods}

A series of 4 months of concurrent data from all four stations for Lloyd's D-season (November 2011 to February 2012) is used to investigate EEJ variability. Location of the observatories used in the study is shown in Figure 1, and the details are listed in Table 1, filling a longitudinal gap in the Asian electrojet zone.

Three component variation data recorded at a 1-min sampling interval by fluxgate magnetometers have been retrieved, and the horizontal component ' $\mathrm{H}$ ' was analyzed in the present study, i.e., from November 2011 to February 2012. One-minute data samples are averaged to obtain $1 \mathrm{~h}$ values centered at 00:30 LT hours for the present work. The respective monthly averaged hourly variation at the four sites for November 2011 is shown 


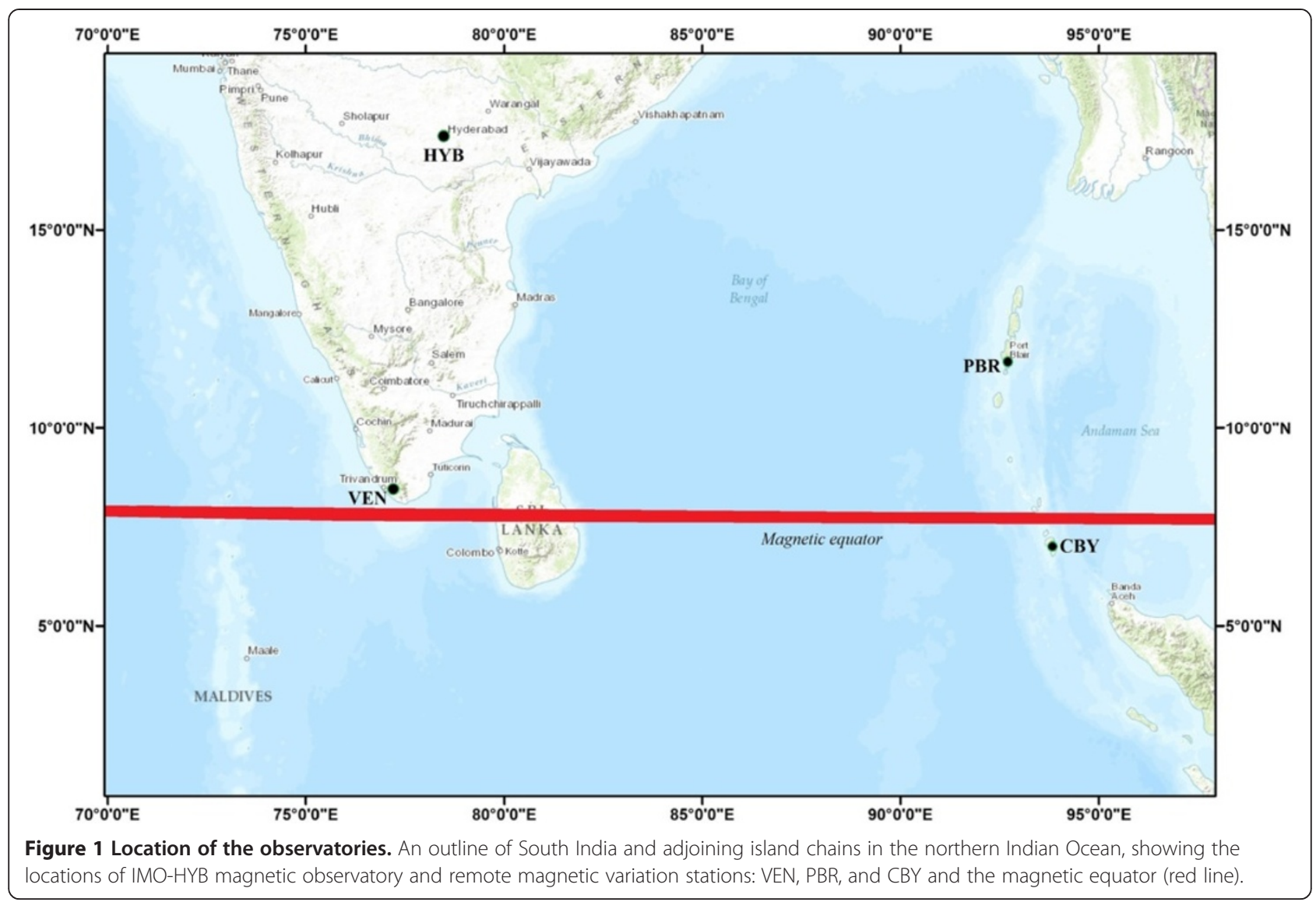

in Figure 2a in UT, showing the time lag between noon peak values at the respective longitudes. On the $\mathrm{x}$-axis, the centered values are labeled as 01:00, 02:00...24:00 LT hours in the figures. The noontime peak first appears at $93^{\circ} \mathrm{E}(\mathrm{CBY}$ and $\mathrm{PBR})$ at $05: 00 \mathrm{UT}$ and later at $77^{\circ} \mathrm{E}$ (VEN and HYB) at 06:00 UT. The difference in time of occurrence is due to the 1-h longitudinal separation between the EEJ pairs. The diurnal variation of the $\mathrm{H}$ component is observed to have the same pattern at each station, with smooth increase from the night level to noontime peak and smooth decrease back to the night level. The amplitude of diurnal variations is higher at equatorial sites, i.e., CBY (approximately $110 \mathrm{nT}$ ) and VEN (approximately $80 \mathrm{nT}$ ) compared to that at low- latitude stations: PBR (60 nT) and HYB (50 nT); the monthly averaged diurnal variations are significantly higher at CBY than VEN. Figure $2 b$ shows the sudden impulse (SI) at 21:50 UT during a strong geomagnetic storm on 28 November 2011 at all the sites concurrently. These observations are utilized to verify the accuracy of the data from the three remote sites after comparing with the INTERMAGNET Hyderabad magnetic observatory (IMO-HYB).

The longitudinal correction approximately 1 -h has been applied to reduce the data of the four sites from UT to corresponding LT to achieve match of the noontime peaks in the two data sets. The hourly averages in LT for all days during the period of study are used in the subsequent analyses.

Table 1 Geographic and geomagnetic coordinates of the observatories used in the study

\begin{tabular}{|c|c|c|c|c|c|c|c|}
\hline & Code & $\begin{array}{c}\text { Geographic } \\
\text { latitude }\end{array}$ & $\begin{array}{l}\text { Geographic } \\
\text { longitude }\end{array}$ & $\begin{array}{l}\text { Dip } \\
\text { angle }\end{array}$ & $\begin{array}{c}\text { Geomagnetic } \\
\text { latitude }\end{array}$ & $\begin{array}{c}\text { Geomagnetic } \\
\text { longitude }\end{array}$ & $\begin{array}{l}\text { Dip } \\
\text { latitude }\end{array}$ \\
\hline Vencode, Kanyakumari & VEN & $8.15^{\circ}$ & $77.10^{\circ}$ & $2.2^{\circ}$ & $-0.29^{\circ}$ & $149.9^{\circ}$ & $1.1^{\circ}$ \\
\hline $\begin{array}{l}\text { Campbell Bay, Nicobar } \\
\text { Islands }\end{array}$ & CBY & $07.00^{\circ}$ & $93.52^{\circ}$ & $-1.98^{\circ}$ & $8.94^{\circ}$ & $166.4^{\circ}$ & $-0.99^{\circ}$ \\
\hline $\begin{array}{l}\text { Hyderabad, Andhra } \\
\text { Pradesh }\end{array}$ & HYB & $17.41^{\circ}$ & $78.55^{\circ}$ & $24.08^{\circ}$ & $2.10^{\circ}$ & $152.1^{\circ}$ & $12.79^{\circ}$ \\
\hline $\begin{array}{l}\text { Port Blair, Andaman } \\
\text { Islands }\end{array}$ & PBR & $11.40^{\circ}$ & $92.45^{\circ}$ & $9.47^{\circ}$ & $-2.58^{\circ}$ & $165.5^{\circ}$ & $4.77^{\circ}$ \\
\hline
\end{tabular}



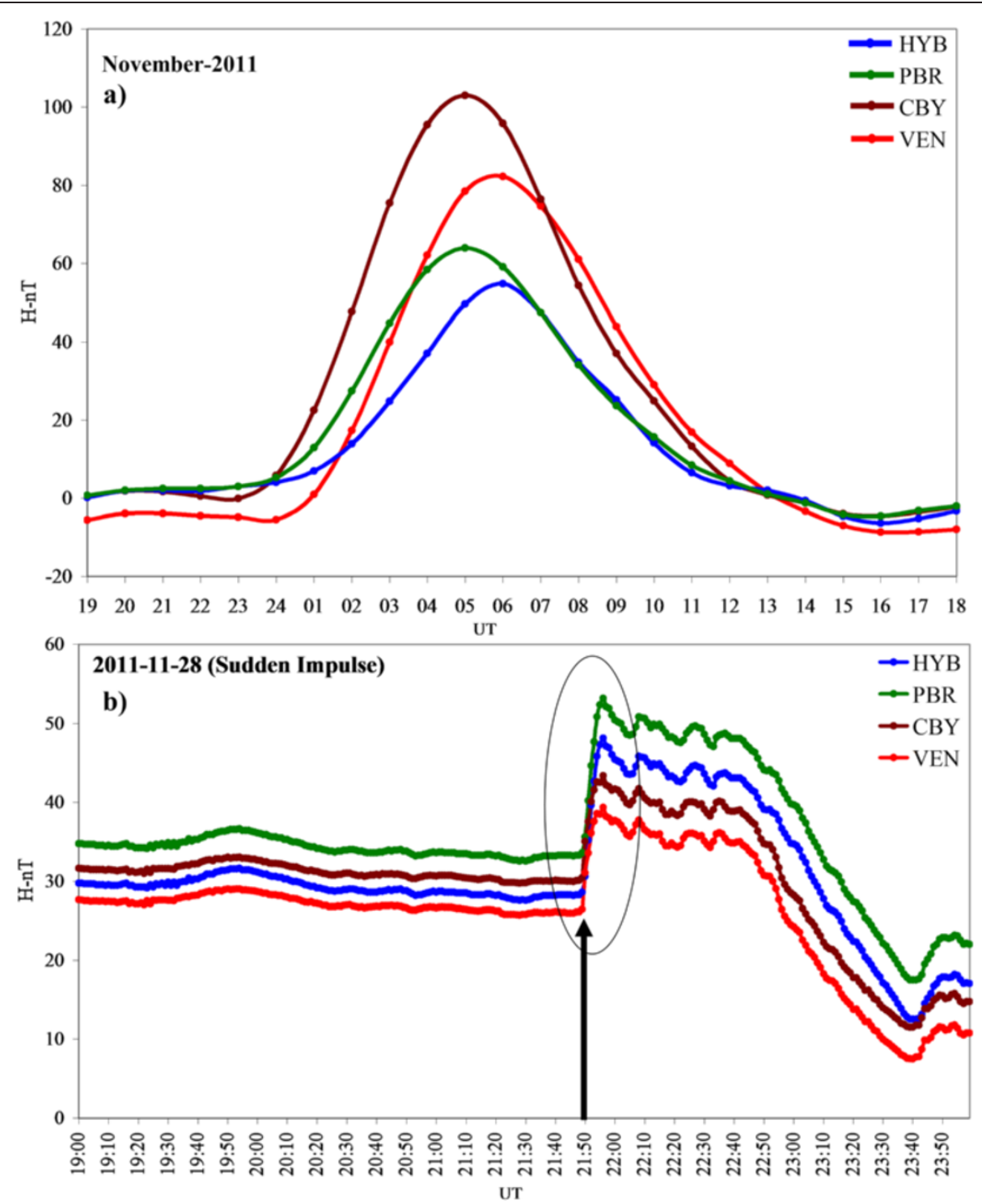

Figure 2 Monthly averaged hourly values and SI. (a) Monthly averaged hourly values of $\mathrm{H}$ component variation of the earth's magnetic field for November 2011, showing the time shift in local time-dependent ionospheric diurnal variation and greater peak amplitudes at equatorial sites, CBY (approximately $110 \mathrm{nT}$ ) and VEN (approximately $80 \mathrm{nT}$ ), compared to that at low-latitude stations: PBR (60 nT) and HYB (50 nT). (b) SI at 21:50 UT during a strong geomagnetic storm on 28 November 2011, a time-independent event recorded simultaneously at all stations.

EEJ variations for each day of the 4 months are obtained by subtracting midnight-mean-removed variation at a lowlatitude station (PBR, HYB) from midnight-mean-removed variation at the EEJ station (CBY, VEN). The midnight means are calculated by taking the average of the 4-h flanking local midnight hours (22:30, 23:30, 00:00, and 01:30). The strength of the EEJ is $\Delta \mathrm{H}=\Delta \mathrm{H}_{\mathrm{EEJ}}-\Delta \mathrm{H}_{\text {non-EEJ, where }}$ $\Delta \mathrm{H}$ is the variation of ' $\mathrm{H}$ ' from the midnight mean level for a particular site. This effectively removes the Sq and Dst contribution from CBY and VEN data. Since HYB is at $12.79^{\circ}$ dip latitude and $\mathrm{PBR}$ is at $4.77^{\circ}$ dip latitude, EEJ strength at VEN is overestimated with respect to CBY. This effect of latitudinal influence on $\mathrm{Sq}$ strength is countered by multiplying the HYB data by a factor of $1.051349 \mathrm{nT}$. This value is arrived at from the normalization of the ratio of the ranges of Sq at HYB and PBR on 10 quiet days, from the period of study. Moreover, the effects for the diurnal variations in temperatures at the remote observation sites have been estimated to be in the order of $2 \mathrm{nT}$. Consequently, variabilities in the order of $2 \mathrm{nT}$ have been disregarded for the current study.

In order to study the intrinsic characteristics of the EEJ and CEJ on a day-to-day basis, we have selected data from 10 magnetically quiet days $(03,05,06,09,10,17,18,19$, 20, and 21) on the basis of Kp indices for the month of November 2011. Figure 3a,b is the typical example of 

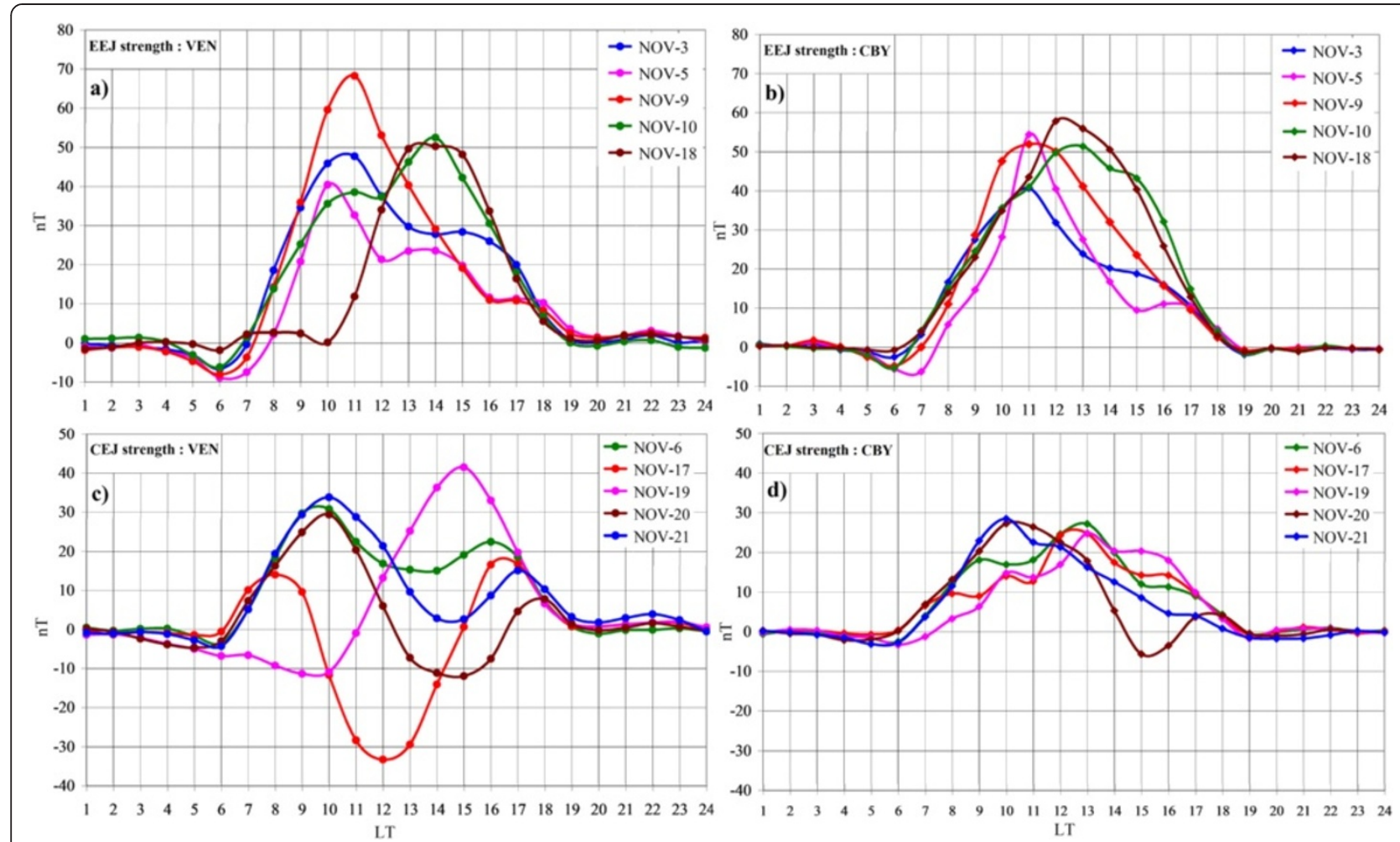

Figure 3 Hourly mean values of EEJ strength for ten quiet days. (a, b) The variability in EEJ strength at VEN (top left panel) and CBY (top right panel) for the days 03, 05, 09, 10, and 18 of November 2011. (c, d) The variability in CEJ strength during the days 06, 17, 19, 20, and 21 of November 2011 at VEN (bottom left panel) and CBY (bottom right panel).

variability in EEJ strength at VEN (top left panel) and CBY (top right panel) during the days $(03,05,09,10$, and 18$)$ of November 2011. On an average, the peak values vary between 40 and $60 \mathrm{nT}$ for both sites, but the time and amplitude of occurrence of noontime peaks of EEJ are not the same at both sites. The spreads of the EEJ events from their buildup to their declines vary from day to day at each site as well as between the longitudes.

A wide range of CEJs is recorded during this period of study. Gouin and Mayaud (1967) and Alex and Mukherjee (2001) categorized the CEJ depending on the time of occurrence as follows: morning counter electrojet (MCE); 07:00 to 10:00 LT), noon counter electrojet (NCEJ; 10:00 to 12:00 LT), afternoon counter electrojet (ACEJ; $12: 00$ to $14: 00 \mathrm{LT}$ ), and evening counter electrojet (ECEJ; $15: 00$ to $18: 00 \mathrm{LT})$. Figure $3 \mathrm{c}, \mathrm{d}$ shows the variability in CEJ phenomena for the days $06,17,19,20$, and 21 of November 2011 at VEN (bottom left panel) and CBY (bottom right panel). It is to be noted that the peak amplitudes of EEJ during CEJ events at VEN $(30.76,16.76,41.51,29.37$, and $33.83 \mathrm{nT})$ and $\mathrm{CBY}(27.15,24.31,24.75,27.23$, and $28.46 \mathrm{nT}$ ) are significantly decreased to values of $30 \mathrm{nT}$ on an average. It is observed that the noontime peak is either advanced or delayed during CEJ occurrence (examples: 19 and 20 November 2011, where NCEJ delayed the peak to 15:00 LT and ECEJ at 15:00 LT advanced the peak to 10:00 LT, respectively). From Figure 3c (bottom left panel), the presence of ACEJ (17 November 2011) at VEN and absence at CBY highlight the variability of CEJ over a spatial separation of approximately $15^{\circ}$ longitude. This event marks the lowest noontime value (16.76 $\mathrm{nT}$ ) at VEN compared to MCEJ and ECEJ events on other days. From the same figure, it is also evident that EEJ variation at CBY is also influenced by the CEJ events recorded at VEN, but the negative amplitudes are small compared to VEN. The event of 20 November 2011 is the best example reflecting the variability in CEJ strength at the sites: VEN (-11.93 nT) and CBY (-5.65 nT) during an ECEJ event.

Models have been developed to present the global picture of the observed signal and aimed to predict the basic features of EEJ signature in longitude, time, dayto-day variations, and seasonal behavior in uncovered regions of ground measurements. These models describe the influence of solar radiation, magnetic activity, conductivity, and atmospheric and seasonal tides on EEJ variations using combined ground, rocket, satellite magnetic measurements (MAG SAT, SAC-C and CHAMP), and radar observations (Onwumechili 1997; Manoj et al. 2006; Alken and Maus 2007; Luhr et al. 2008, 2012). The first 
global model of the EEJ was deduced from the POGO (1967 to 1970) satellite observations (Onwumechilli and Agu 1980). Using the CHAMP satellite data, the longitudinal differences in the behavior of the EEJ influenced by tidal zonal winds (Luhr et al. 2012; Hausler et al. 2013) and other interplanetary fields (Manoj et al. 2008) were revealed. A systematic study of the EEJ characteristics using all the data from the Oersted, CHAMP, and SAC-C satellites obtained during the years (1999 to 2006) was used to construct the equatorial electrojet climatological model (EEJM-2.0) to reflect the day-to-day variability of electrojet using the input parameters of longitude, local time, and season and solar flux. EEJM-2.0 generates current density and conductivity values sampled over every hour (i.e., from 05:00 to 19:00 LT) (Alken and Maus 2007). We have extracted the current densities from EEJM-2.0 for each hour of all days (i.e., from 05:00 to 19:00 LT) for all the 4 months at both longitudes $\left(77^{\circ}\right.$ and $\left.93^{\circ}\right)$, based on calculated real-time extreme ultraviolet flux model for aeronomic calculation (EUVAC) (Richards et al. 1994) values (http://omniweb.gsfc.nasa.gov/ form/dx1.html). The observed EEJ strengths and modeled current densities are compared in the subsequent analyses.
Correlation between the EEJM-2.0 and EEJ strength at $77^{\circ}$ and $93^{\circ}$ longitudes

The monthly averaged hourly means (i.e., from 05:00 to 19:00 LT) of the global current density model from EEJM-2.0 for each month during the period of study are plotted in terms of local time and longitude along the dip equator at an average height of approximately 100 to $120 \mathrm{~km}$, corresponding to the E-region of ionosphere, as shown in Figure 4. The panels show that, globally, the longitudinal variations of current density change considerably with season; two peaks are seen in November 2011 (Figure 4a) and February 2012 (Figure 4d) whereas three intensity peaks are seen in December 2011 (Figure 4b) and January 2012 (Figure 4c). The seasonal average is shown in Figure 4e. The average EEJ current density distribution for noontime conditions derived from CHAMP measurements show large diurnal variations occurring at certain longitudes, example, at $90^{\circ} \mathrm{W}$ and $90^{\circ} \mathrm{E}$ (Luhr et al. 2008). The black vertical lines in Figure 4 indicate the longitudes of CBY and VEN. At this longitudinal separation, the model predicts that current density is greater at CBY than VEN throughout
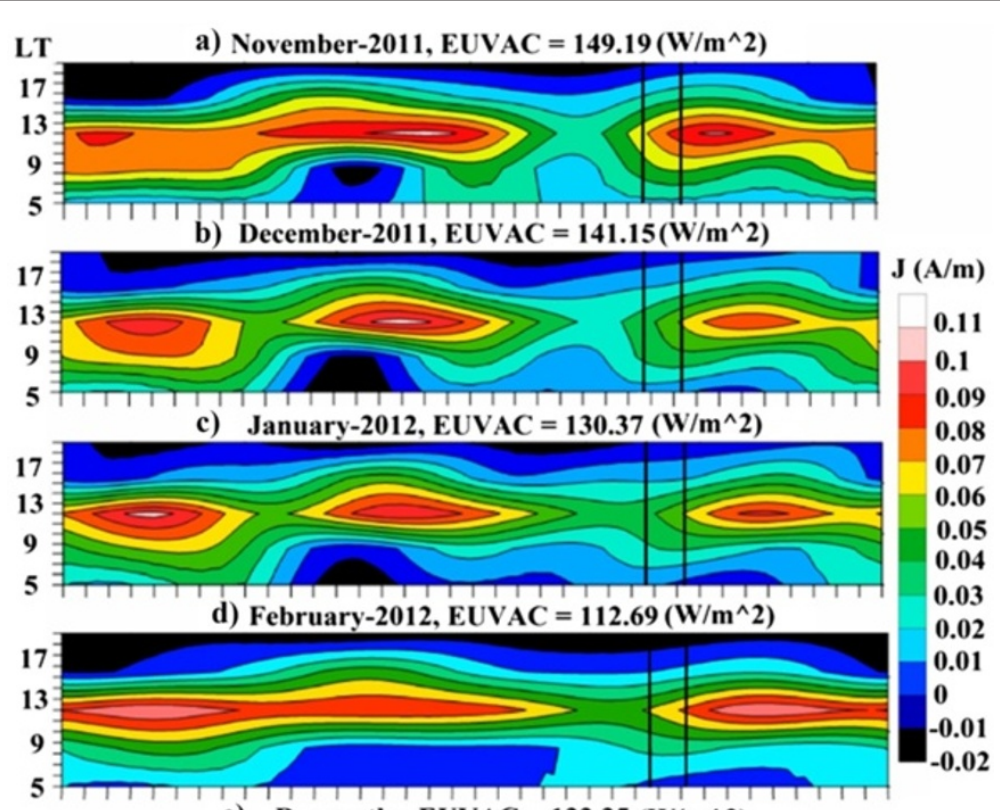

e) D- months, EUVAC $=133.35\left(\mathrm{~W} / \mathrm{m}^{\wedge} 2\right)$

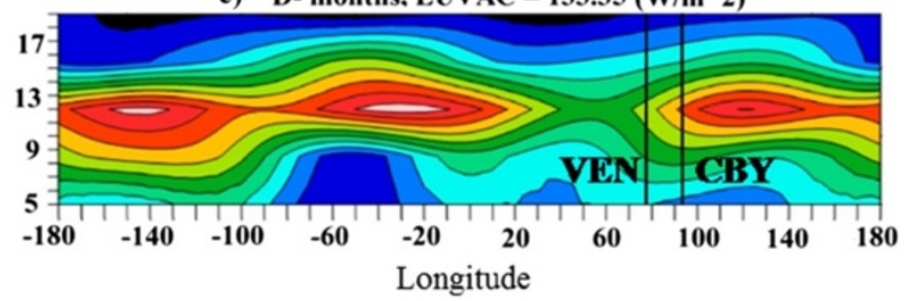

Figure 4 Monthly averaged daily variation of global current density derived from the EEJM-2.0 model. Monthly averaged daily variation of global current density from 05:00 to 19:00 LT of EEJ derived from EEJM-2.0 model for (a) November 2011, (b) December 2011, (c) January 2012, and (d) February 2012. (e) D-season averaged. The black lines mark the EEJ longitudes of VEN and CBY. 
the D-season. Luhr et al. (2008) observed that this longitudinal pattern follows those of the peaks caused by the non-migrating diurnal eastward and westward propagating tides of the upper atmosphere with zonal wave number 3 (DE2 and DW2). However, considerable relative variation is seen from month to month.

The monthly averaged hourly means (i.e., from 05:00 to 19:00 LT) of the observed EEJ strengths at VEN and CBY (top right and left panels, Figure 5a,b) and derived current density values for VEN and CBY (bottom right and left panels, Figure 5c,d) are shown in Figure 5. The EEJM-2.0 model predicts the EEJ strength well at these longitudes. The variability in EEJ strength between the sites, VEN and CBY, is clearly brought out from Figure 5a,b. For CBY (Figure $5 \mathrm{~b}$ ), the observed peak amplitudes are considerably larger for all the 4 months compared to VEN (Figure 5a). The delineation of noontime peaks at VEN is different from that at CBY during November 2011 to January 2012 (Figure $5 \mathrm{a}, \mathrm{b}$ ) with a time shift. The EEJM-2.0 predicts the similar current densities at both longitudes. The densities are lower during the end of December to beginning of January 2012 compared to other months. Comparison of Figure $5 \mathrm{a}$ with $5 \mathrm{c}$ and Figure $5 \mathrm{~b}$ with $5 \mathrm{~d}$ brings out the differences in the nature of EEJ variations at the sites vis-àvis the variations of the corresponding current density. The differences become increasingly marked from around 10:00 to 17:00 LT between the two data sets at the two longitudes.

\section{Characteristic features of day-to-day EEJ variability at VEN and $\mathrm{CBY}$}

The EEJ strengths at CBY and VEN are compared with the derived daily noontime peak current densities at respective longitudes for all days of the 4 months and plotted in Figure 6a,b,c,d. In November 2011 (Figure 6a), the current densities for both longitudes indicate a smooth downward trend (CBY is greater than VEN), with a constant difference of about $0.02(\mathrm{~A} / \mathrm{m})$. The observed EEJ strengths at CBY and VEN for November 2011 show large day-to-day fluctuations (order of 10 $\mathrm{nT}$ ). The differences in EEJ amplitudes between the two sites are significant on many days, i.e., CBY is greater than VEN, except for 9 days $(03,08,09,11,12,15,23$, 27, and 28 November 2011; amplitudes at VEN is greater than CBY). The negative peak amplitudes correspond to the occurrences of strong CEJ events on some days, as evident from visual inspection (Figure 3c,d).

For December 2011 (Figure 6b), the daily variability at both sites remains large; EEJ strength is larger at CBY except for 2 days $(2,27)$. In January 2012, the EEJ strength at CBY is greater than VEN, except for 11 days $(04,06,07$, $10,12,15,16,23,26,28$, and 31) (Figure 6c), and EEJ amplitudes are greater at VEN on 6 days: $01,08,19,23,25$, and 26 in February 2012 (Figure 6d). Over the 4 months of study, the variations in EEJ amplitudes fluctuate between 5 and $30 \mathrm{nT}$. The current density shows smooth decreasing trend in December and slightly increasing trends during January and February, with CBY values being higher than VEN.

The modeled current density from EEJM-2.0 and observed variations of EEJ strength are not well correlated at the two longitudes on a day-to-day basis. The observed day-to-day variability between the two EEJ longitudes from the Figure 6 is further examined with reference to Kp values (http://spidr.ngdc.noaa.gov/spidr/). We classified the days according to Kp values into three segments: (i) the very quiet day $(\mathrm{Kp}<1)$, (ii) quiet day $(\mathrm{Kp}<2)$, and (iii) moderately disturbed days $(\mathrm{Kp}>2)$. Out of a total of

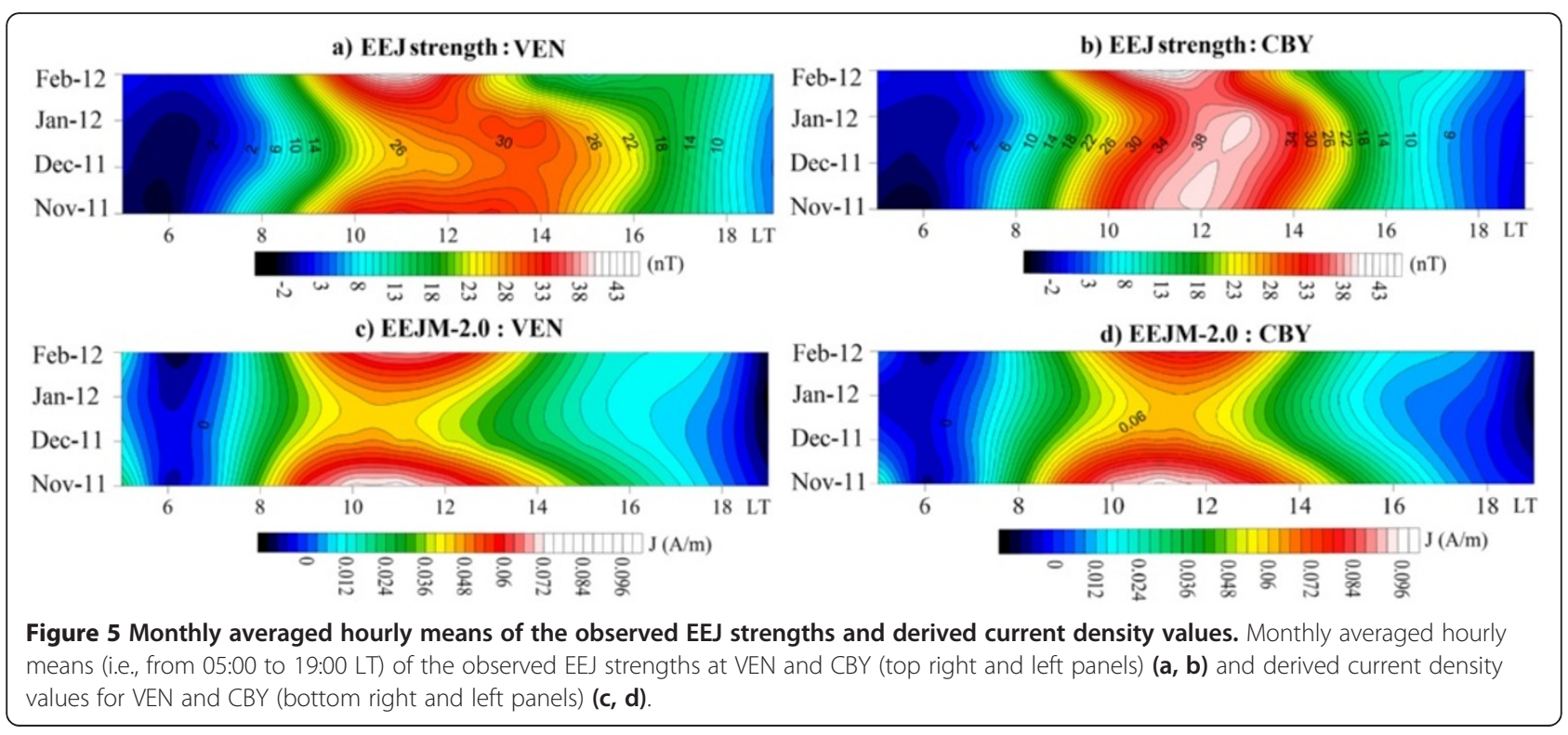



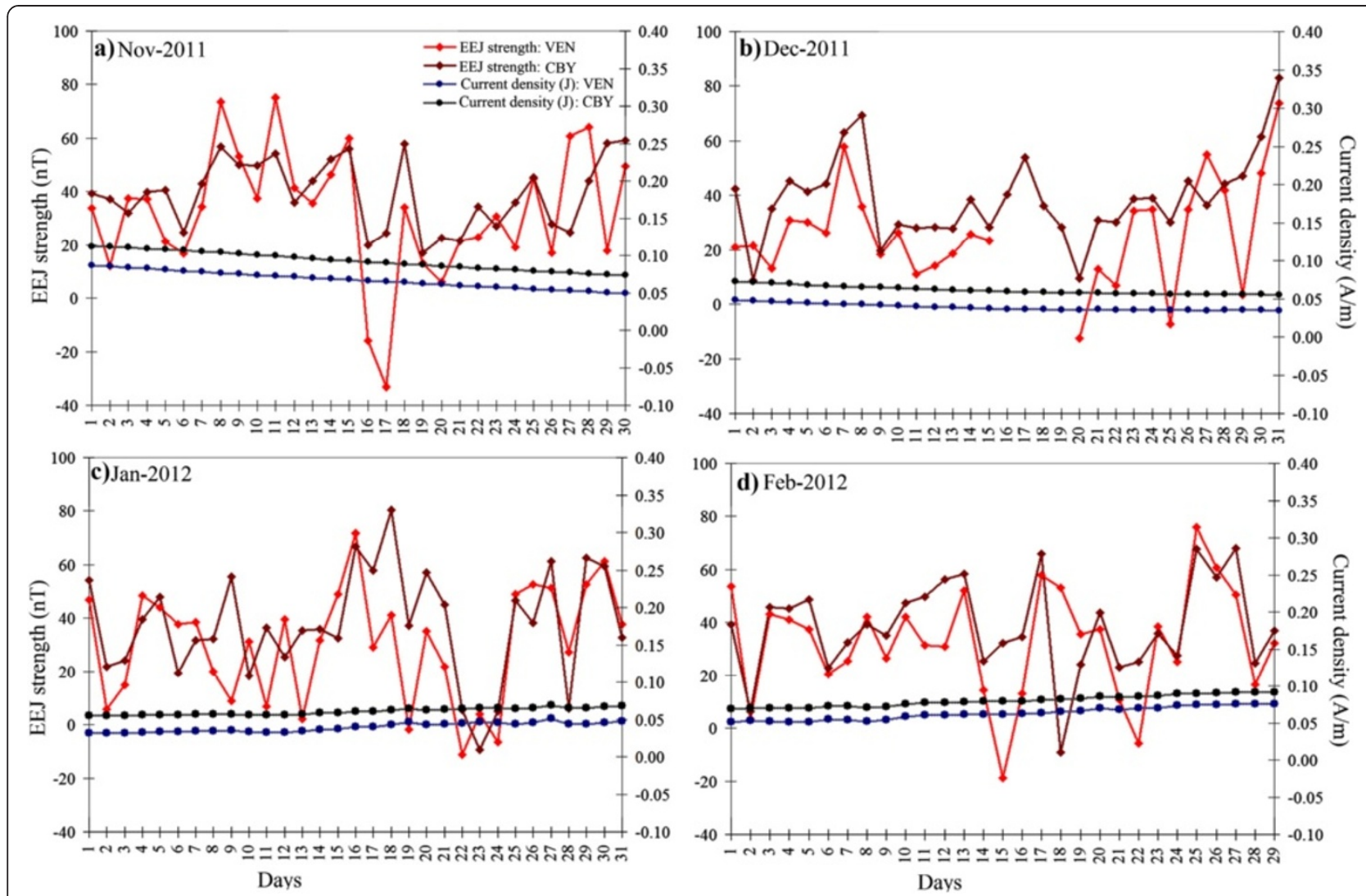

Figure 6 Noontime EEJ strength on all days of each month along with the noontime current density. Noontime EEJ strength on all days of each month at VEN (red) and CBY (brown) along with the noontime current density from EEJM-2.0 for (a) November 2011, (b) December 2011, (c) January 2012, and (d) February 2012. Solid black color represents the (A/m) for CBY and blue color for VEN.

121 days of this study, on 90 days, the EEJ strength is higher at CBY than at VEN and for 28 days, it is higher at VEN than at CBY. With the remaining 3 days, the difference between the noontime amplitudes falls less than 2 $\mathrm{nT}$ and is not considered here. We found a total of 41 days for $\mathrm{Kp}<1,54$ days for $\mathrm{Kp}<2$, and 23 days for $\mathrm{Kp}>2$ from November 2011 to February 2012. The observed variability in EEJ strength between the two longitudes during Dseason is shown in Figure 7 on the basis of Kp values. The black bar shows the number of days when the EEJ strength at CBY is greater than VEN, and gray bar shows the number of days when the EEJ strength at VEN is greater than CBY. The magnitude of differences between CBY and VEN is indicated. From Figure $7 \mathrm{a}(\mathrm{Kp}<1)$, out of 40 days where CBY is greater than VEN, at least 18 days show a large difference $>10 \mathrm{nT}$. For $\mathrm{Kp}<2$, Figure $7 \mathrm{~b}$, out of 40 days where CBY is greater than VEN, 20 days show differences $>10 \mathrm{nT}$. In Figure 7c, out of 20 days where CBY is greater than VEN, 11 days are observed with EEJ differences $>10 \mathrm{nT}$. Additionally, on 11 days $(\mathrm{Kp}<1)$, peak amplitude of VEN is greater than CBY (Figure 7a), and for $\mathrm{Kp}<2,14$ days observed with VEN is greater than CBY. For approximately $50 \%$ of the days, EEJ at CBY is greater than VEN by more than $10 \mathrm{nT}$. This further substantiates the high degree of day-to-day variability between the two longitudes.

The hour-to-hour variability of EEJ strength between the two longitudes is quantified by calculating the correlation coefficients $(r)$ for each of the hours (09:00 to 18:00 LT) during each month of D-season, shown in Table 2. In November 2011, correlation is strong $(r>$ 0.6) during 09:00 to 17:00 LT. During December 2011, correlation is strong during 12:00 to 17:00 LT and weak during the other hours. In January 2012, correlation is strong during 10:00 and 12:00 to 17:00 LT and weak during the other hours. During February 2012, correlation is weak at all hours.

\section{Characteristic features of CEJ at VEN and CBY}

We have provided examples of EEJ and CEJ events in Figure 3 to illustrate the fluctuations of the CEJ phenomena. Four selected examples of EEJ and CEJs, at both VEN and CBY, are shown in Figure 8. Figure 8a shows a typical EEJ, and Figure $8 \mathrm{~b}$ is an example of an MCEJ occurring at both stations. Figure $8 \mathrm{c}$ shows a strong NCEJ of $-40 \mathrm{nT}$ at VEN, which is not evident at 

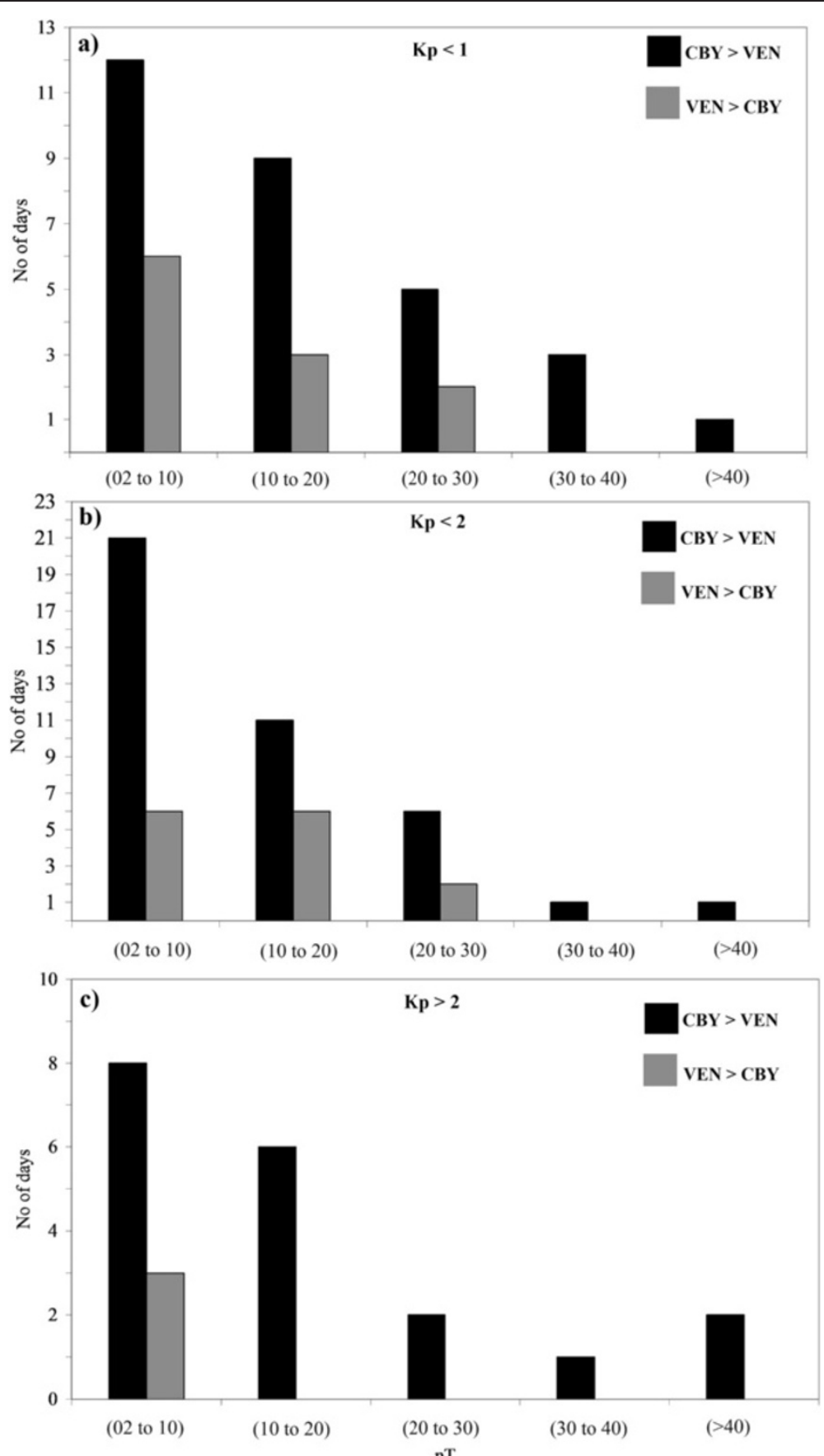

Figure 7 The observed variability in EEJ strength between the two longitudes during D-season. Graph showing the differences in noontime peak values of EEJ strength between VEN and CBY, sorted on the basis of the daily mean of planetary index (Kp), i.e., Kp $<1$ (a), Kp $<2$ (b), and Kp > 2 (c) for the months November 2011 to February 2012. Black color represents the number of days with higher amplitudes for CBY > VEN and gray color for VEN $>$ CBY.

CBY, although the strength of EEJ is diminished to 37 nT. Figure 8d is an example of an ECEJ, which is seen at both sites.

All the CEJ occurrences, for both sites, have been shown in Figure 9 for each month. The identification of CEJ events has been noted by manual inspection of $\Delta \mathrm{H}$ for each station with occurrence time and amplitude. Red color symbols represent the CEJ at VEN and dark brown at CBY. Each symbol represents the variants of CEJ ( MCEJ; - NCEJ; $\triangle$ ACEJ; • ECEJ). There are few CEJ events during November 2011 (Figure 9a), recorded with greater amplitude (negative) at VEN than at CBY, 
Table 2 Computed correlation coefficients ( $r$ ) of EEJ strength at VEN and CBY for each hour [09:00 to 18:00 LT] for the months November 2011 to February 2012

\begin{tabular}{lcccccccccc}
\hline Months & $\mathbf{0 9 : 0 0 ~ L T ~}$ & $\mathbf{1 0 : 0 0 ~ L T ~}$ & $\mathbf{1 1 : 0 0 ~ L T ~}$ & $\mathbf{1 2 : 0 0 ~ L T ~}$ & $\mathbf{1 3 : 0 0 ~ L T ~}$ & $\mathbf{1 4 : 0 0 ~ L T ~}$ & $\mathbf{1 5 : 0 0 ~ L T ~}$ & $\mathbf{1 6 : 0 0 ~ L T ~}$ & $\mathbf{1 7 : 0 0 ~ L T ~}$ & $\mathbf{1 8 : 0 0 ~ L T}$ \\
\hline November 2011 & 0.78 & 0.76 & 0.77 & 0.63 & 0.80 & 0.85 & 0.82 & 0.84 & 0.84 & 0.57 \\
December 2011 & 0.54 & 0.45 & 0.51 & 0.73 & 0.69 & 0.67 & 0.79 & 0.82 & 0.78 & 0.18 \\
January 2012 & 0.58 & 0.63 & 0.49 & 0.60 & 0.80 & 0.85 & 0.84 & 0.87 & 0.67 & 0.25 \\
February 2012 & 0.21 & 0.23 & 0.39 & 0.55 & 0.58 & 0.56 & 0.51 & 0.55 & 0.48 & 0.14 \\
\hline
\end{tabular}

i.e., two MCEJ events on 16 and 19, one ACEJ on 17 and one ECEJ on 29 November 2011 at VEN but absent at CBY. One ECEJ event is evident at both sites on 20 November 2011, whereas on 01 November, ECEJ is at CBY but absent at VEN and on 29 November, the ECEJ is at VEN and not at CBY. During December (Figure 9b), two MCEJs (01 and 06 December) and one ACEJ (25 December) are present at VEN and not seen at CBY. The days 20 and 29 of December 2011 show the occurrence of ACEJ and ECEJ at both stations. The CEJ events on days 13, 14, 30 (MCEJ), 19, 20 (NCEJ), and 22 (ECEJ) of January 2012 were completely absent at CBY shown in (Figure 9c). The same MCEJ events were identified at both stations on days 17 and 28 and ACEJ on 23 and 24 for January 2012. During February 2012 (Figure 9d), three ECEJ events are recorded at both stations (days 16, 21, and 29) and one ACEJ (02). The days, 22 (MCEJ), 11, 15, 18 (ACEJ), and 28 (ECEJ) of February 2012, are recorded at VEN and not at CBY. Two ECEJ events on days 22 and 24 were identified at CBY and not at VEN. No NCEJ events are observed during November, December 2011, and February 2012.

A total of $43 \mathrm{CEJ}$ events were identified; out of which, 12 MCEJ, 2 NCEJ, 14 ACEJ, and 15 ECEJ are recorded at the longitudes during the period of study. A total of 28 and 15 CEJ events are observed in VEN and CBY,
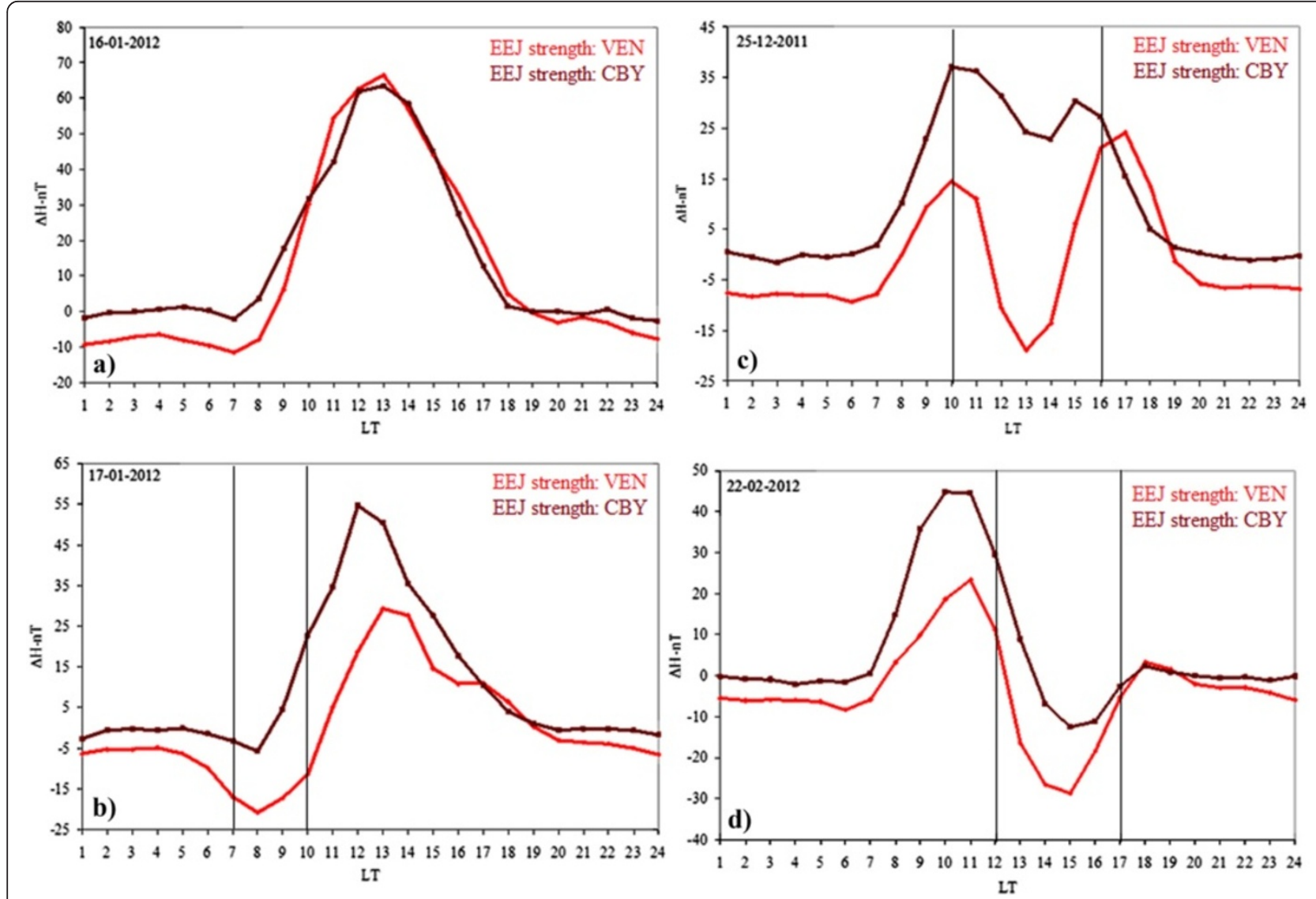

Figure 8 EEJ and CEJs at both VEN and CBY. (a) Daily variation of EEJ strength at VEN (65 nT) and CBY (63 nT) on 16 January 2012. (b) The morning CEJ event on 17 January 2012, of amplitude -20 nT at VEN and (-4 nT) at CBY. (c) Afternoon CEJ (ACEJ) with amplitude -20 nT at VEN and absence of ACEJ on 25 December 2011. (d) Evening CEJ at VEN (-30 nT) and (-15 nT) at CBY during 22 February 2012. 


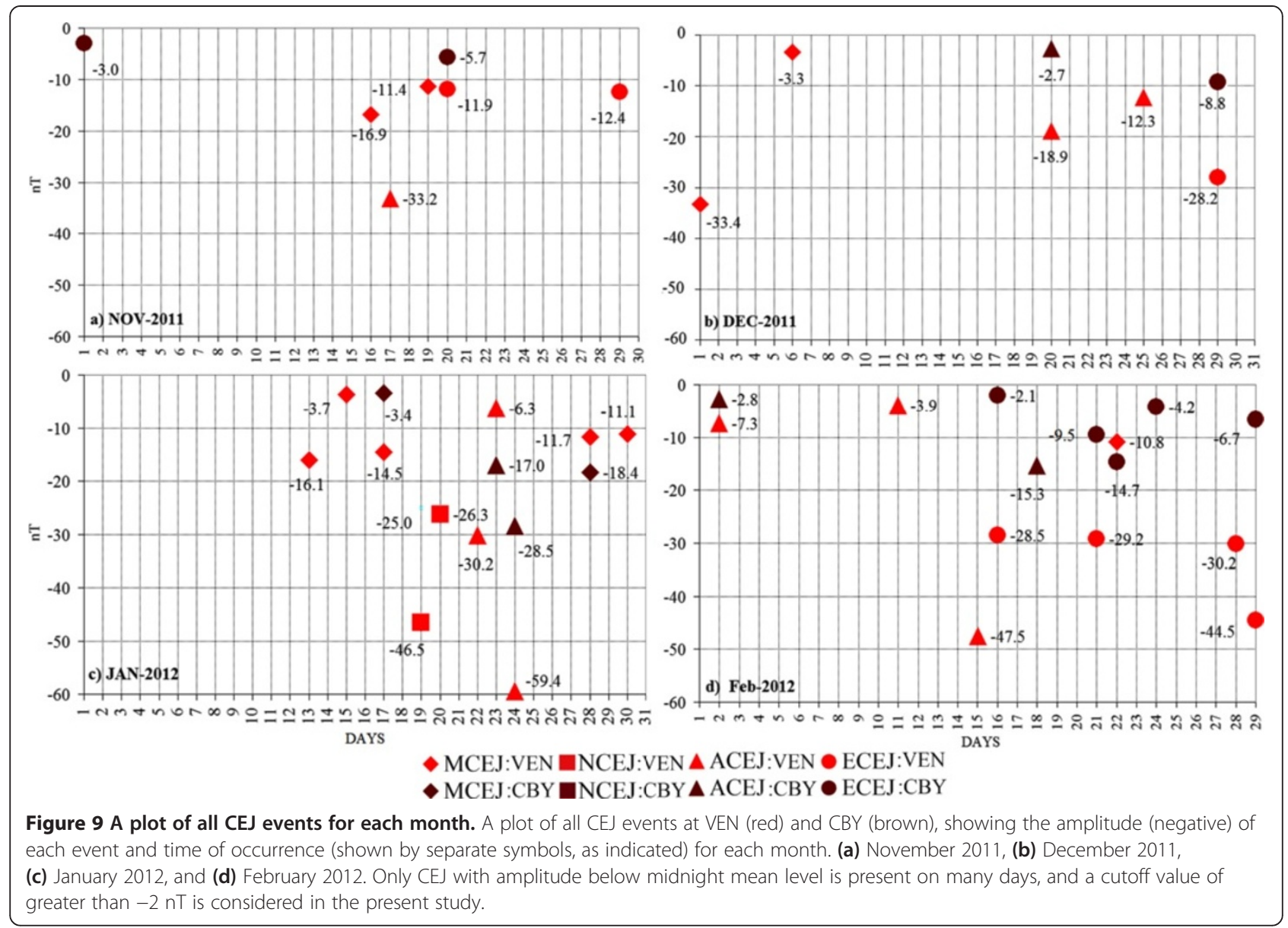

respectively, during the 4 months of the study. From Table 3, it is seen that most of the CEJs are observed during quiet days $\mathrm{Kp}<1,2$ (32 events; 23 days) than moderately disturbed days, i.e., $\mathrm{Kp}>2$ (11 events; 8 days). Individually, 10, 2 (MCEJ); 2, 0 (NCEJ); 9, 5 (ACEJ); and 7, 8 (ECEJ) are observed at VEN and CBY, respectively. From the same table and Figure 6, it is evident that many CEJ events are present at VEN and absent at CBY on quiet and disturbed days. The presence of CEJs of amplitude $<-5 \mathrm{nT}$ influence the strength of the EEJ at both longitudes. This is evident in the reduced amplitudes of EEJ at VEN (Figures 3 and 6) as compared to $\mathrm{CBY}$ on the days of occurrence of significant CEJ events (Figure 9).

\section{Results and discussion}

New data at closely spaced EEJ sites and comparison with EEJM-2.0

A new set of electrojet pairs used in the present study (VEN-HYB and CBY-PBR) formed the first such set of observations of magnetic variations, separated by $15^{\circ}$ longitude and were compared with the monthly averaged values of current densities over the northern Indian
Ocean from global EEJM-2.0 (Figure 4). The observed monthly averaged EEJ amplitudes correlated well with the global model EEJM-2.0 at the two longitudes (Figure 5). The noontime EEJ strength shows a smooth decrease in D-season up to December and a gradual increase from January, approaching the equinoctial maximum of daily variation (Figure 6). Global averaged current densities for each month as well as D-season average (Figure 4) show the persistence of larger current strength at $93^{\circ}$ longitude compared to $77^{\circ}$. The trends of the monthly averaged hourly means of current density from EEJM-2.0 match the monthly averaged hourly means of EEJ strengths at both the longitudes (Figure 5). Inspection of the top and bottom panels of Figure 5 shows that EEJM-2.0 corresponds very well with the EEJ strengths at VEN and CBY in the morning hours (i.e., from 05:00 to 09:00 LT). In the evening hours (i.e., from 14:00 to 19:00 LT), there are noticeable differences between the data sets during all the 4 months; both in terms of amplitudes as well as the irregular trends of the contours of EEJ at VEN and CBY, seen in the top panels, indicating the local differences at VEN and CBY, which are not reflected in the near congruous trends of the EEJM-2.0 in the bottom panels. Thus, the 
Table 3 List of observed CEJ events and their characteristics at both longitudes with reference to Kp index

\begin{tabular}{|c|c|c|c|c|c|}
\hline Month & Day & $K p<1$ & CEJ & VEN & CBY \\
\hline November 2011 & 16 & 0.75 & MCEJ & Yes & - \\
\hline November 2011 & 17 & 0.93 & ACEJ & Yes & - \\
\hline November 2011 & 19 & 0.04 & MCEJ & Yes & - \\
\hline November 2011 & 20 & 0.26 & ECEJ & Yes & Yes \\
\hline December 2011 & 6 & 0.16 & MCEJ & Yes & - \\
\hline December 2011 & 25 & 0.70 & ACEJ & Yes & - \\
\hline January 2012 & 15 & 0.95 & MCEJ & Yes & - \\
\hline January 2012 & 19 & 0.49 & NCEJ & Yes & Yes \\
\hline January 2012 & 20 & 0.99 & NCEJ & Yes & - \\
\hline February 2012 & 16 & 0.95 & ECEJ & Yes & Yes \\
\hline \multirow[t]{2}{*}{ February 2012} & 18 & 0.80 & ACEJ & Yes & - \\
\hline & & $\mathrm{Kp}<2$ & & & \\
\hline December 2011 & 1 & 1.68 & MCEJ & Yes & - \\
\hline December 2011 & 20 & 1.38 & ACEJ & Yes & Yes \\
\hline January 2012 & 13 & 1.54 & MCEJ & Yes & - \\
\hline January 2012 & 17 & 1.43 & MCEJ & Yes & - \\
\hline January 2012 & 23 & 1.76 & ACEJ & Yes & - \\
\hline January 2012 & 28 & 1.50 & MCEJ & Yes & Yes \\
\hline January 2012 & 30 & 1.39 & MCEJ & Yes & Yes \\
\hline February 2012 & 2 & 1.16 & ACEJ & Yes & Yes \\
\hline February 2012 & 11 & 1.08 & ACEJ & Yes & - \\
\hline February 2012 & 21 & 1.68 & ECEJ & Yes & Yes \\
\hline February 2012 & 24 & 1.34 & ECEJ & Yes & - \\
\hline \multirow[t]{2}{*}{ February 2012} & 29 & 1.38 & ECEJ & Yes & Yes \\
\hline & & $\mathrm{Kp}>2$ & & & \\
\hline November 2011 & 1 & 3.30 & ECEJ & Yes & - \\
\hline November 2011 & 21 & 2.45 & ECEJ & Yes & - \\
\hline December 2011 & 29 & 2.00 & ECEJ & Yes & Yes \\
\hline January 2012 & 22 & 3.43 & ACEJ & Yes & - \\
\hline January 2012 & 24 & 2.95 & ACEJ & Yes & Yes \\
\hline February 2012 & 15 & 3.41 & ACEJ & Yes & - \\
\hline February 2012 & 22 & 2.23 & MCEJ, ECEJ & Yes & Yes \\
\hline February 2012 & 28 & 2.20 & ECEJ & Yes & - \\
\hline
\end{tabular}

discrepancies between the trends as well as the amplitudes from model and the data, particularly during the afternoon hours (i.e., from 10:00 to 13:00 LT), are highly prominent in Figure 5a,b, compared to Figure 5c,d, which highlight the nature of EEJ variability at a longitudinal separation of $15^{\circ}$.

Comparison of EEJ fluctuations with estimated current density from the model at respective longitudes further highlights the fact that noontime variability in EEJ strength is not accounted for in EEJM-2.0 (Figure 6). The days when EEJ strength differs from the model also varies considerably more at VEN. This is illustrated in Figures 3, 5, and 6, where variability from day to day and averaged hourly means over the months, for both stations are shown. The variability is generally larger at VEN. This suggests the influence of local meteorological mechanisms, viz., departures/oscillations of the wave structure of atmospheric tides, which are not incorporated in EEJM-2.0. These tides and fluctuations of the eastward and westward winds have been associated with ionospheric parameters (Sridharan et al. 2002; Lin et al. 2007; Luhr et al. 2008; Vichare and Rajaram 2011; Luhr et al. 2012). While this dataset has been analyzed to study the effects of longitudinal separation, the possible influence of local topography and meteorological considerations has not been quantified to make an assessment.

\section{Large day-to-day longitudinal variability between the sites in D-season}

On sorting EEJ strengths according to Kp values (Figure 7), it is noted that for more than $30 \%$ of the days, the amplitude difference between CBY and VEN is greater than 10 $\mathrm{nT}$, which is significant, being approximately $20 \%$ of the averaged EEJ amplitude. A close examination of Figure 6 also shows that noontime EEJ strengths at VEN and CBY are poorly correlated during most of the second half of November 2011, December 2011, first half of January 2012, and few days in February 2012, in agreement with earlier findings (Greener and Schlapp 1979; Alken and Maus 2007). Figure 7 emphasizes the relative degrees of variability of the two longitudes vis-à-vis the number of days. In some earlier analyses, a drop in correlation over longitudinal separation approximately 15 to 20 degrees has been noted (Schlapp 1968; Manoj et al. 2006; Alken and Maus 2007). These analyses showed symmetric reduction of correlation with increasing distance between the longitudes (east and west) of observation. Therefore, it is likely that greater influence of wave-tidal interactions having spatial scales of approximately $1,000 \mathrm{~km}$ could be invoked to explain day-to-day variability (England et al. 2006; Abdu et al. 2006). These authors have also suggested planetary wave (PW) oscillations of different periodicities with episodic nature have been observed to occur simultaneously in the mesospheric winds and EEJ intensity. The interaction of gravity waves and non-migrating tides has been noted from observations using air glow and MF radar (Vineeth et al. 2012; Gurubaran et al. 2001; Sridharan et al. 2002), which indicate interactions between planetary wave oscillations and shifts in duration and time of EEJ maximum strength. The zonal distribution of surface heat flux and precipitating clouds is not uniform around the globe and leads to the generation of non-migrating tidal oscillations, in the lower atmosphere, propagating both westward and eastward, or standing (Tsuda and Kato 1989). To a lesser extent, local factors affecting lower atmospheric 
neutral winds could also influence E-region dynamics through lower-upper atmospheric coupling, as low-latitude observations have revealed the existence of non-migrating tides even at mesospheric levels (Sasi and Krishnamurthy 1993). Immel et al. (2006) conclude that neutral winds in the lower atmosphere influence and modulate the E-region dynamo to produce spatial variability approximately $1,000 \mathrm{~km}$ scales. Other causes of EEJ variability suggested by earlier workers are (i) the variations in tidal strength (Stening 1975) and the sharp longitudinal gradients in the diurnal non-migrating tides (DE2 and DW2) between the longitudes over $15^{\circ}$ separation (Anderson et al. 2009); (ii) the day to day variability of zonal winds (Fang et al. 2008); (iii) the day-to-day variability in semidiurnal tide at lower thermosphere, modulated by interactions at planetary wave periodicities (Fuller-Rowell et al. 2008); and (iv) the modulation of ionospheric dynamo in the middle atmosphere through the excitation of solar non-migrating tides in the troposphere (Jin et al. 2011).

\section{CEJ events}

A total of $43 \mathrm{CEJ}$ events were identified in this 4-month season. Some significant patterns are the large number of small amplitude CEJ events occurring almost daily (Figure 9), the absence of CEJ events at CBY $\left(93^{\circ}\right)$ longitude (examples: 01 and 16 November and 01 December 2011) which were recorded at VEN and simultaneous events at both longitudes (examples: 20 November and 20 and 29 December 2011) during the period of study. The presence of westward currents during daytime results in decrease of the eastward electrojet (examples: November 2011 to January 2012 at VEN) in the morning and (i.e., from 08:00 to 10:00 LT) evening hours (i.e., from 14:00 to 16:00 LT) and shifting of the noontime peak to 13:00 LT, seen in Figure 5a (for November 11 to January 12) and for January 2012 at CBY (Figure 5b) to 13:00 LT. From Table 3, it is evident that most of the observed CEJ events are during $\mathrm{Kp}<1$ (13 events) and $K \mathrm{p}<2$ (20 events), highlighting the variability in occurrence phenomena of CEJ during quiet days.

It is evident that the CEJ occurrences are more frequent and higher in amplitude at VEN than CBY (Figure 9), which is a new finding and important contribution of this work. The persistence of CEJ events at VEN but not at CBY indicate the influence of local effects such as: eastward zonal winds (Ramkumar et al. 2002), gravity wave-tidal interactions, and vertical coupling process in mesosphere lower thermosphere ionosphere (MLTI) resulting in neutral winds (Vineeth et al. 2007; Liu and Watanabe 2008) via DE3 tidal modulation of the E-layer dynamo, changes in temperature, wind and density variation in the upper mesospheric region due to the influence of tides, gravity, and planetary waves from the stratosphere and troposphere (Vineeth et al. 2012), which strongly influence ionospheric conductivity over short spatial scales of approximately
$1,600 \mathrm{~km}$. The present observations reinforce the previous works of Rastogi (1973), Raghavarao and Anandarao (1987), Rangarajan and Rastogi (1993), suggesting that the phenomena of depression of $\mathrm{X}$ or $\mathrm{H}$ component of the magnetic field at electrojet stations during morning hours are localized events and in some occasions, the events may not occur on the same day even at locations separated by a longitude of 2 to $3 \mathrm{~h}$ (i.e., more than 3,000 km). Kane (1973), Kane and Trivedi (1981), and Rastogi (1974) found that CEJs have a small longitudinal extent of less than 3,000 km. Rangarajan and Rastogi (1993) observed that CEJ events at observatories separated by $35^{\circ}$ are not always in agreement. Variability in occurrence of CEJs could also be due to the differences in local wind shears that modify jet fields (especially during the noon hours), (Reddy and Devasia 1981) in addition to the observed changes in neutral winds (Sridharan et al. 2002; Vineeth et al. 2007). Whether there is a predominance of CEJs in the westward direction requires analysis of data from at least one more western longitude along with measurements of associated ionospheric parameters which is planned to be the future work.

\section{Conclusions}

The current study presents for the first time observations that document the variability in EEJ at separation of $15^{\circ}$ longitude with two new remote electrojet sites in India. The EEJ strengths observed at VEN and CBY are compared with the current density of EEJM-2.0. While the difference in current densities at the two sites is constant, the EEJ strength at these sites exhibit differences, both on monthly averaged values as well as daily values. Day-to-day variability could be up to $30 \mathrm{nT}$ (almost 50\% of the signal strength). These observations provide evidence of local influences over a separation of 1,600 km.

Short spatial variability of equatorial electrojet on the earth's magnetic field plays a key role in understanding dynamics of the atmosphere-ionosphere coupling. Several mechanisms can cause the longitudinal variations in EEJ strength: tidal effects in the ionosphere, low-latitude signatures of magnetic activity, planetary wave oscillations, interaction of gravity waves and non-migrating tides and day to day variability of zonal winds. The role of atmospheric/meteorological effects in ionospheric variability is being studied and quantified with ever increasing accuracy of the present satellite observations. Real time ground observations of ionospheric changes may provide critical inputs to further probe the factors for the variability.

A large number of CEJ events recorded in this dataset exhibit a distinct difference in occurrence pattern at VEN and CBY, suggesting that various CEJ currents are influenced by local effects that are associated with the coupling process of troposphere-stratosphere mechanisms generated 
by atmospheric tidal winds over a short duration of one hour. Some mechanisms in lower/upper atmosphere have been observed to directly influence the eastward electrojet. Some are sporadic and some are periodic. The influence of each cannot be quantified from the present study.

\section{Competing interests}

The authors declare that they have no competing interests.

\section{Authors' contributions}

NPC, NN, and KA participated in the design and data acquisition. NN and NPC analyzed and interpreted the database. NPC, NN, and KA drafted the manuscript and subsequent revisions. All authors read and approved the final manuscript.

\section{Acknowledgements}

The data acquisition for this work was supported by the SIP (001228) of the CSIR Eleventh Five Year Plan. The fellowships (NPC and NN) were provided by the Ministry of Earth Sciences, GOI, project (MoES/P.O.(Seismo)/1(124)/ 2010), and GENIAS (PSC0104) project of CSIR-NGRI of the Twelfth Five Year Plan. The authors thank the following persons and agencies: Shri. S.R. Sannasi, Shri. K Chandrasekhar Rao, and Smt. L. Manjula for their assistance in the data acquisition and baseline measurements (CSIR-NGRI): Shri. P. Sai Vijaykumar towards the installation of EEJM-2.0 software (CSIR-NGRI); Dr. P.B.V. Subba Rao for lending a magnetometer for the initial period of observations (IIG, Mumbai); and Bethany Navajeevan High School (Vencode), Department of Science \& Technology and Conservator of Forests, Andaman and Nicobar administration for observations and assistance in maintaining the instruments. The author (NPC) would like to thank Prof. P. Rama Rao, Professor, Department of Geophysics, Andhra University, India, and Dr. P.S. Bramhanandam, National Central University, Taiwan, towards the support for this study. Additionally, the authors thank Dr. YJ. Bhaskar Rao, Acting Director, CSIR-National Geophysical Research Institute for support and permission to publish this work.

Received: 17 February 2014 Accepted: 28 August 2014 Published: 8 September 2014

\section{References}

Alex S, Mukherjee S (2001) Local time dependence of the equatorial counter electrojet effect in a narrow longitudinal belt. Earth Planets Space 53:1151-1161

Alken P, Maus S (2007) Spatio-temporal characterization of the equatorial electrojet from CHAMP, Orsted and SAC-C satellite measurements. J Geophys Res 112:A09305, doi:10.1029/2007JA012524

Anderson D, Araujo-Pradere E, Scherliess L (2009) Comparing daytime, equatorial $E \times B$ drift velocities and TOPEX/TEC observations associated with the 4-cell, non-migrating tidal structure. Ann Geophys 27:2861-2867

Abdu MA, Batista PP, Batista S, Brum CGM, Carrasco AJ, Reinisch BW (2006) Planetary wave oscillations in mesospheric winds, equatorial evening pre reversal electric field and spread F. Geophys Res Lett 33, L07107, doi:10.1029/2005GL024837

Adimula A, Rabiu AB, Yumoto Y, the MAGDAS Group (2011) Geomagnetic field variations from some equatorial electrojet stations. Sun Geosphere 6:39-43

Bhargava BN, Sastri NS, Arora BR, Rajaram R (1980) The afternoon counter-electrojet phenomenon. Ann Geophys 36:231-239

Chapman S (1951) The equatorial electrojet as detected from the abnormal electric current distribution above Huancayo and elsewhere. Arch Meteorl Geophys Bioclimatol A4:368-392

Cohen Y, Achache J (1990) New global vector magnetic anomaly maps derived from MAGSAT data. J Geophys Res 95(B7):10783-10800, doi:10.1029/ JB095iB07p10783

Cain JC, Sweeney RE (1973) The POGO data. J Atmos Terr Phys 35:1231-1247, doi:10.1016/0021-9169(73)90021-4

Doumouya V, Vassal J, Cohen Y, Fambitakoye O, Menviell M (1998) Equatorial electrojet at African longitudes: first results from magnetic measurements. Ann Geophys 16:658-676

Egedal J (1947) The magnetic diurnal variations of the horizontal force near the magnetic equator. Terre Magn Atmos Electr 52:449-451

England SL, Maus S, Immel TJ, Mende SB (2006) Longitudinal variation of the E-region electric fields caused by atmospheric tides. Geophys Res Lett 33, L21105, doi:10.1029/2006GL027465
Fambitakoye O, Rastogi RG, Tabbagh J, Vila P (1973) Counter electrojet and Esq disappearance. J Atmos Terr Phys 35:1119-1126, doi:10.1016/0021-9169(73)90009-3

Fang TW, Richmond AD, Liu JY, Maute A (2008) Wind dynamo effects on ground magnetic perturbations and vertical drifts. J Geophys Res 113, A11313, doi:10.1029/2008JA013513

Francisca ON, Esther Hanson A, Eucharia Okoro C, Isikwue BC, Oby Ugonabo J (2013) Formation and identification of counter electrojet. Int J Phys Sci 8(15):604-612

Fuller-Rowell TJ, Akmaev RA, Wu F, Anghel A, Maruyama N, Anderson DN, Codrescu MV, Iredell M, Moorthi S, Juang HM, Hou YT, Millward G (2008) Impact of terrestrial weather on the upper atmosphere. Geophys Res Lett 35, L09808, doi:10.1029/2007GL032911

Gouin P, Mayaud PN (1967) Apropos de 1' existens possible d'un counter electrojet aux latitudes equatorials. Ann Gephys 23:41-50

Greener JG, Schlapp DM (1979) A study of day to day variability of Sq over Europe. J Atmos Terr Phys 41:217-223

Gurubaran S, Sridharan S, Ramkumar TK, Rajaram R (2001) The mesospheric quasi-2-day wave over Tirunelveli (8.7 N). J Atmos Sol-Terr Phy 63:975-985

Hausler K, Oberheide J, Luhr H, Koppmann R (2013) The geospace response to nonmigrating tides. In: Lubken F-J (ed) Climate and Weather of the Sun-Earth System (CAWSES): highlights from a priority program. Springer, Dodrecht, the Netherlands, pp 481-506

Immel TJ, Sagawa E, England SL, Henderson SB, Hagan ME, Mende SB, Frey HU, Swenson CM, Paxton $\sqcup$ (2006) Control of equatorial ionospheric morphology by atmospheric tides. Geophys Res Lett 33, L15108, do:10.1029/2006GL026161

Jadhav G, Rajaram M, Rajaram R (2002) A detailed study of equatorial electrojet phenomenon using Orsted satellite observations. J Geophys Res 107(A8): doi:10.1029/2001JA000183. issn: 0148-0227

Jin H, Miyoshi Y, Fujiwara H, Shinagawa H, Terada K, Terada N, Ishii M, Otsuka Y, Saito A (2011) Vertical connection from the tropospheric activities to the ionospheric longitudinal structure simulated by a new Earth's whole atmosphere-ionosphere coupled model. J Geophys Res 116, A01316, doi:10.1029/2010JA015925

Kane RP (1973) Comparison of geomagnetic changes in India and the POGO data. J Atmos Terr Phys 35:1249-1252, doi:10.1016/0021- 9169(73)90022-6

Kane RP, Trivedi NB (1981) Implication of Z variations during a near noon equatorial counter electrojet on March 6, 1967 in the Indian sector. J Geophys Res 85:470-710

Kikuchi T, Hashimoto KK, Kitamura TI, Tachihara H, Fejer B (2003) Equatorial counter electrojets during substorms. J Geophys Res 108(A11):1406, doi:10.1029/2003JA009915

Langel RA, Pucker M, Rajaram M (1993) The equatorial electrojet and associated currents as seen in Magsat data. J Atmos Terr Phys 55:1233-1269

Liu HL, Roble RG (2002) A study of a self-generated stratospheric sudden warming and its mesospheric-lower thermosphereic impacts using the coupled TIME-GCM/CCM3. J Geophys Res 107(D23):4695

Luhr H, Rother M, Hausler K, Alken P, Maus S (2008) The influence of nonmigrating tides on the longitudinal variation of the equatorial electrojet. J Geophys Res 113(812), A08313, doi:10.1029/2008JA013064

Luhr H, Rother M, Hausler K, Fejer B, Alken P (2012) Direct comparison of non migrating tidal signatures in the electrojet, vertical plasma drift and equatorial ionization anomaly. J Atmos Sol-Terr Phy 75-76:31-43

Liu H, Watanabe S (2008) Seasonal variation of the longitudinal structure of the equatorial ionosphere: does it reflect tidal influences from below? J Geophys Res 113, A08315, doi:10.1029/2008JA013027

Lin CH, Hsiao CC, Liu JY, Liu CH (2007) Longitudinal structure of the equatorial ionosphere: time evolution of the four-peaked EIA structure. J Geophys Res 112, A12305, doi:10.1029/2007JA012455

Mayaud PN (1977) The equatorial counter electrojet-a review of its magnetic aspects. J Atmos Terr Phys 39:1055-1070

Marriot RT, Richmond AD, Venkateswaram SV (1979) The quiet time equatorial electrojet and counter electrojet. JGeomag Geoelectr 31:311-340

Manoj C, Luhr H, Maus S, Nagarajan N (2006) Evidence for short spatial correlation lengths of the noontime equatorial electrojet inferred from a comparison of satellite and ground magnetic data. J Geophys Res 111, A11312, doi:10.1029/2006JA011855

Manoj C, Maus S, Luehr H, Alken P (2008) Penetration characteristics of the interplanetary electric field to the day-time equatorial ionosphere. J Geophys Res doi:10.1029/2008JA013381

Matsuno T (1971) A dynamical model of the stratospheric sudden warming. J AtmosSCi 28:1479-1494, doi:10.1175/1520-0469 (1971)02801479:ADMOTS42.0. CO;2

McCreadie H (2004) Classes of the equatorial electrojet. In: Reigbaret al C (ed) Earth Observation with CHAMP: Results From Three Years in Orbit. Springer, Berlin, pp 401-406 
Onwumechilli CA, Agu CE (1980) Longitudinal variation of equatorial electrojet parameters derived from POGO satellite observations. Planet Space Sci 29:627-634

Onwumechili CA, Akasofu SI (1972) On the abnormal depression of Sq (H) under the equatorial electrojet in the afternoon. J Geomagn Geoelectr 24:161-173

Onwumechili CA (1985) Satellite measurements of the equatorial electrojet. J Geomagn Geoelectr 37:11-36

Onwumechili CA (1997) The equatorial electrojet, Gordon and Breach. Published 1997 CRC Press, Newark, N. J., http://books.google.com/books? id=kwCFPH4C3tEC. ISBN 9056990691

Rastogi RG (1962) Longitudinal variation in the equatorial electrojet. J Atmos Terr Phys 24:1031-1040

Rastogi RG (1973) Counter equatorial electrojet in the Indian zone. Planet Space Sci 21:1355-1365

Rastogi RG, Chandra H (1974) Interplanetary magnetic field and the equatorial ionosphere. J Atmos Terr Phys 36:377-379

Rastogi RG (1974) Westward equatorial electrojet during daytime hours. J Geophys Res 79(10):1503-1512, doi:10.1029/JA079i010p01503

Rangarajan GK, Rastogi RG (1993) Longitudinal difference in magnetic field variations associated with quiet day counter electrojet. J Geomagn Geoelectr 45:649-656

Rastogi RG, Chandra H, Chakrabarty D, Kitamura K, Yumoto K (2007) Day-to-day variability of the equatorial electrojet current in the South American sector. Earth Planets Space 59:459-461

Richards PG, Fennelly JA, Torr DG (1994) EUVAC: a solar EUV flux model for aeronomic calculations. J Geophys Res 99(A5):8981-8992

Reddy CA, Devasia CV (1981) Height and latitude structure of electric fields and currents due to local east-west winds in the equatorial electrojet. J Geophys Res 86:5751-5767

Raghavarao R, Anandarao BG (1987) Equatorial electrojet and the counter electrojet. Ind J Rad Space Phys 16:54-75

Ramkumar TK, Gurubaran S, Rajaram R (2002) Lower E-region MF radar spaced antenna measurements over magnetic equator. J Atmos Solar-Terr Phys 64:1445-1453

Schlapp DM (1968) World-wide morphology of day-to-day variability of Sq. J Atmos Terr Phys 30:1761-1776

Sizova LZ (2002) The field-aligned currents effect on equatorial geomagnetic field variations. Adv Space Res 30:2247-2252

Somayajulu W, Cherian L, Rajeev K, Ramkumar G, Reddi CR (1993) Mean winds and tidal components during counter electrojet events. Geophys Res Lett 20 (14):1443-1446, doi:10.1029/93GL00088

Sridharan S, Gurubaran S, Rajaram R (2002) Structural changes in the tidal components in the mesospheric winds as observed by the MF radar during afternoon counter electrojet events. J Atmos Sol Terr Phys 64:1455-1463, doi:10.1016/S1364-6826(02)00109-8

Sridharan R, Sathishkumar S, Gurubaran S (2009) Variabilities of mesospheric tides and equatorial electrojet strength during stratospheric warming events. Ann Geophys 27:4125-4130, doi:10.5194/angeo-27-4125-2009

Stening RJ (1975) Problems of identifying lunar geomagnetic effects at Huancayo. J Geomagn Geoelectr 27:409-424

Sasi MN, Krishnamurthy BV (1993) An observational study of middle atmospheric tides over Trivandrum (8.5 $\left.\mathrm{N}, 77^{\circ} \mathrm{E}\right)$. J Geomagn Geoelectr 45:547-561

Tsuda T, Kato S (1989) Diurnal non-migrating tides excited by a different heating due to land-sea distribution. J Meteorol Soc Jpn 67:43-45

Vichare G, Rajaram R (2011) Global features of quiet time counter electrojet observed by Orsted. J Geophys Res 116, A04306, doi:10.1029/2009JA015244

Vineeth C, Pant TK, Devasia CV, Sridharan R (2007) Highly localized cooling in daytime mesopause temperature over the dip equator during counter electrojet events: first results. Geophys Res Lett 34, L14101, doi:10.1029/2007GL030298

Vineeth C, Pant TK, Hossain MM (2012) Enhanced gravity wave activity over the equatorial MLT region during counter electrojet events. Indian J Radio Space $41: 258-263$

doi:10.1186/1880-5981-66-110

Cite this article as: Chandrasekhar et al.: Evidence of short spatial variability of the equatorial electrojet at close longitudinal separation. Earth, Planets and Space 2014 66:110. 